\title{
The effects of dietary intake of essential fatty acids on prostaglandin and leukotriene synthesis
}

\author{
By G. A. Higgs, Department of Prostaglandin Research, Wellcome Research \\ Laboratories, Beckenham, Kent $B R_{3}{ }_{3} B S$
}

During the last 25 years prostaglandins and, more recently, leukotrienes have commanded increasing interest in the field of medical research. The identification of these substances as potent local hormones which contribute to many physiological and pathological processes has made them the target for potential new therapies. An understanding of the origin of prostaglandins and leukotrienes has led to the suggestion that dietary manipulation could be a means of controlling their synthesis and that this may be of prophylactic value in diseases such as thrombosis and arthritis. In the present paper I shall discuss the relation between essential fatty acids, prostaglandins and leukotrienes and indicate how essential fatty acid intake could influence events in the development of thrombotic and inflammatory disorders.

\section{Production of prostaglandins}

Prostaglandins were discovered at approximately the same time as the essential fatty acids. In 1937, Von Euler gave the name 'prostaglandin' to a pharmacologically active substance extracted from human semen which he thought was derived from the prostate gland. We now know that the enzymes which synthesize prostaglandins are widely distributed in mammalian tissues. It was not, however, until 1960 that Bergstrom \& Sjovall $(1960 a, b)$ identified prostaglandins $\mathrm{E}$ and $\mathrm{F}$ as cyclized fatty acids. The similarity between these prostaglandin structures and $\mathrm{C}_{20}$ polyunsaturated fatty acids led to the proposal that prostaglandins were derived from essential fatty acids. It was then demonstrated that dihomo- $\gamma$-linolenic acid $\left(\mathrm{C}_{20: 3}\right)$ and arachidonic acid $\left(\mathrm{C}_{20: 4}\right)$ could be converted to prostaglandins in vitro (Bergstrom et al. 1964; Van Dorp et al. 1964).

The biochemical mechanisms of prostaglandin (PG) synthesis have now been elucidated (for review, see Samuelsson et al. 1978). Molecular oxygen is incorporated into $\mathrm{C}_{20}$ fatty acids in a dioxygenase reaction which is catalysed by cyclo-oxygenase ( $E C$ 1.1 4.99.1). The initial step is abstraction of hydrogen at $\mathrm{C}-\mathrm{I} 3$ and peroxidation at $\mathrm{C}-\mathrm{I} \mathrm{I}$ which is followed by addition of oxygen at $\mathrm{C}-\mathrm{I} 5$ and ring closure between $\mathrm{C}-8$ and $\mathrm{C}-12$ to form unstable cyclic endoperoxides $\left(\mathrm{PGG}_{2}\right.$ and $\mathrm{PGH}_{2}$; Fig. 1).

Cyclic endoperoxides are transformed to different products in different tissues. In platelets and neutrophils, thromboxane is generated from the endoperoxides (Hamberg et al. 1975) while in blood vessels the major cyclo-oxygenase product is prostacyclin (Moncada et al. 1976; Fig. I). Prostaglandins of the D and E series 
(a) Cyclo-oxygenase

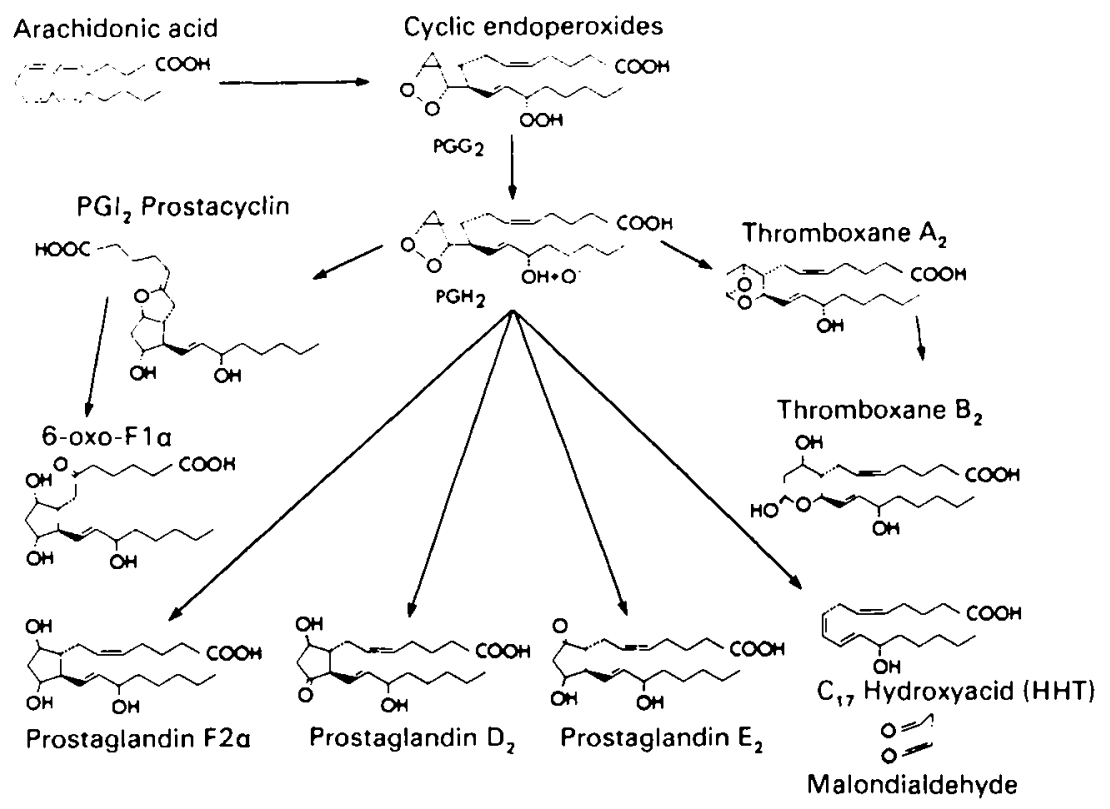

(b) Lipoxygenase pathways<smiles>CCCCCCCC(O)/C=C/CCCC(O)/C=C\CCC(=O)O</smiles>

Leukotriene $B_{4}(5,12-$ DHETE)

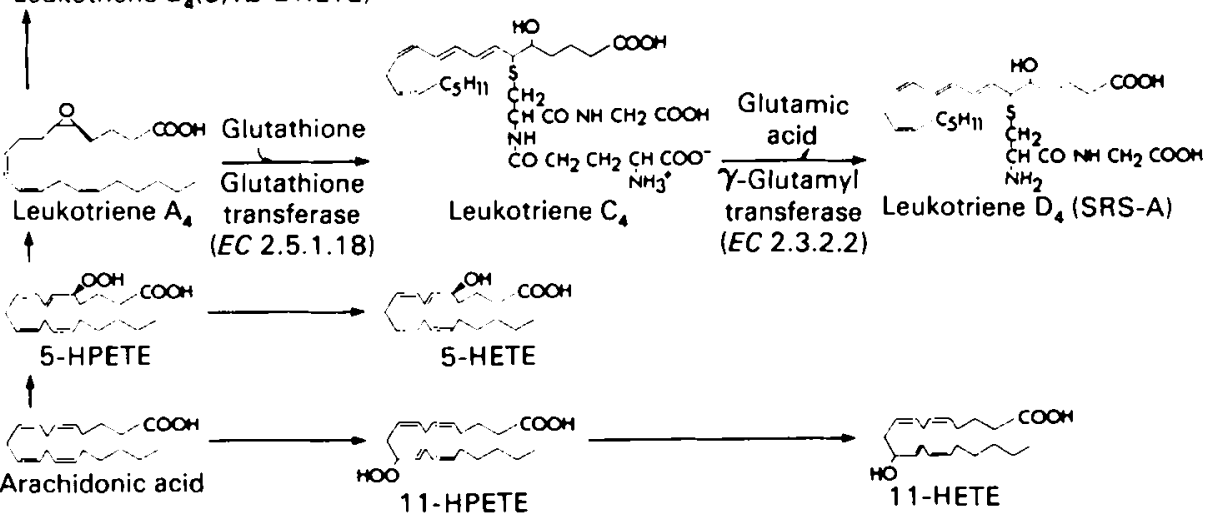

Fig. 1. Metabolism of arachidonic acid by (a) cyclo-oxygenase (EC 1.14.99.1) and (b) lipoxygenase (EC 1.13.11.12) pathways.

6-oxo-F $I_{\alpha}$, 6-oxo-prostaglandin $\mathrm{F}_{\mathrm{I}_{a}}$; HHT, hydroxyheptadecatrienoic acid; SRS-A, slowreacting substance of anaphylaxis; HETE, hydroxy-eicosatetraenoic acid; DHETE, dihydroxyeicosatetraenoic acid; HPETE, hydroperoxy-eicosatetraenoic acid. I I-HPETE and I1-HETE: $12-$ and 15 -HPETE and $12-$ and 15 -HETE may be formed by similar routes. 
are generated by isomerases found in most tissues and F-type prostaglandins are formed by reductive cleavage of the endoperoxides.

There is a high degree of substrate specificity for cyclo-oxygenase, which has a high affinity for $C_{20}$ unsaturated fatty acids whereas $C_{19}$ or $C_{21}$ fatty acids are relatively poor substrates (Van Dorp, 1967). Also, cyclo-oxygenase has a greater affinity for $\mathrm{C}_{20: 4}$ than $\mathrm{C}_{20: 3}$ or $\mathrm{C}_{20: 5}$. The products formed from these substrates differ by the number of double bonds present and this is denoted by a numerical suffix. For example, $\mathrm{C}_{20: 3}$ is the precursor of prostaglandin $E_{1}, C_{20: 4}$ of $P_{G} E_{2}$ and $\mathrm{C}_{20: 5}$ of $\mathrm{PGE}_{3}$.

\section{Production of leukotrienes}

There are alternative pathways of fatty acid peroxidation which lead to the formation of non-prostaglandin substances. In the absence of cyclo-oxygenase, peroxidation at C-I I or C-I 5 results in the production of open-chain hydroperoxy acids which can then be metabolized to hydroxy acids. Platelets contain an enzyme which converts arachidonic acid to 12-hydroxy-eicosatetraenoic acid (12-HETE; Fig. I) (Hamberg \& Samuelsson, 1974; Nugteren, 1975). It is now known that similar lipoxygenase ( $E C$ I.I 3.I I.12) reactions can catalyse the formation of up to six different hydroxy acids from arachidonate.

The study of lipoxygenase activity in polymorphonuclear leucocytes (PMNs) revealed that peroxidation at $\mathrm{C}_{-5}$ is a major pathway of $\mathrm{C}_{20}$ fatty acid metabolism in those cells (Borgeat et al. 1976; Borgeat \& Samuelsson, 1979). The 5 -hydroperoxide was found to be converted to a 5,6-epoxide with a conjugated triene structure (leukotriene $A_{4} ;$ Fig. 1 ). Samuelsson and his colleagues then characterized a series of hydroxy acids and peptido-lipids derived from this epoxide which they name the 'leukotrienes' because of their source and structure (Samuelsson, 1983 ). Leukotrine B is a simple dihydroxy fatty acid but leukotriene $\mathrm{C}, \mathrm{D}$ and $\mathrm{E}$ are formed following the addition of glutathione to leukotriene $\mathrm{A}$ (Fig. I). The leukotrienes contain the same number of double bonds as their fatty acid precursors and, in common with cyclo-oxygenase products, this is denoted by a numerical suffix; such that leukotriene $A_{3}$ is derived from $C_{20: 3}$ leukotriene $A_{4}$ from $\mathrm{C}_{20: 4}$ and leukotriene $\mathrm{A}_{5}$ from $\mathrm{C}_{20: 5}$.

\section{The role of cyclo-oxygenase in thrombosis}

Following the demonstration that prostaglandins were derived from essential fatty acids, the possibility of unstable intermediates being formed in this process was investigated. Piper \& Vane (1969) detected an unstable rabbit aorta contracting substance (RCS) in the effluent of isolated perfused lungs following anaphylactic challenge. This substance could not be matched by a known prostaglandin. When the cyclic endoperoxides were trapped and isolated they were shown to have many of the biological properties of RCS but did not account for all the biological activity observed. The discrepancies were resolved with the identification of thromboxane $\mathrm{A}_{2}$ (TXA $\mathrm{TX}_{2}$; Fig. I) which was shown to have potent vasoconstrictor properties (Hamberg et al. 1975). $\mathrm{TXA}_{2}$ is produced by platelets 
and is a potent platelet-aggregating agent. It is now thought that $\mathrm{TXA}_{2}$ is a major mediator of platelet activation and hence thrombus formation.

The search for thromboxane synthetase in blood vessel walls led to the discovery of a further unstable product derived from cyclic endoperoxides, prostacyclin (Moncada et al. 1976; Fig. I). Prostacyclin, which is the major cyclo-oxygenase product of vascular endothelial cells, prevents platelet aggregation and is a potent vasodilator. It has been proposed that the balance between thromboxane and prostacyclin production is an important mechanism in the maintenance of homeostasis and that prostacyclin is a defensive hormone which protects blood vessel walls from the deposition of platelet thrombi (for review, see Moncada, I982).

\section{The effect of dietary intake of fatty acids on platelet function}

Before the discovery of prostacyclin, $\mathrm{PGE}_{1}$ was the most potent known inhibitor of platelet aggregation. $\mathrm{PGE}_{1}$ is derived from dihomo- $\gamma$-linolenic acid $\left(\mathrm{C}_{20.3}\right)$ which is not widely distributed in mammalian tissue and $\mathrm{PGE}_{1}$ is not normally a significant product of cyclo-oxygenase. Because of the anti-aggregating activity of $\mathrm{PGE}_{1}$ it was suggested that dietary supplementation with $\mathrm{C}_{20: 3}$ could result in decreased platelet responsiveness (Willis et al. 1974). This proposal for modulating thrombus formation has limitations, however, because the endoperoxides formed from $\mathrm{C}_{20: 3}, \mathrm{PGG}_{1}$ and $\mathrm{PGH}_{1}$ cannot be converted to prostacyclin and this would impair the natural defence mechanism.

A more recent suggestion, which is gaining support, is that eicosapentaenoic acid (EPA; $\mathrm{C}_{20: 5}$ ) in the diet could decrease platelet activation. EPA is converted to a prostacyclin-like substance which is probably $\Delta^{17}$ prostacyclin and has a similar anti-aggregating potency to prostacyclin itself (Gryglewski et al. 1979). Thromboxane $A_{3}$ is produced from EPA but this substance is less potent in aggregating platelets than $\mathrm{TXA}_{2}$. There is also evidence that EPA has a direct effect in inhibiting aggregation (Moncada, r 982).

There is also some epidemiological evidence to support the hypothesis that EPA-rich diets protect against thrombosis. The diet of Greenland Eskimos, unlike that of Caucasians, is rich in EPA and this may explain why Eskimos have a lower incidence of acute myocardial infarction and an increased tendency to bleed (Dyerberg \& Bang, 1979). The feeding of volunteers with fish diets, cod-liver oil or EPA supplements results in reduced thromboxane $\mathrm{B}_{2}$ synthesis, decreased platelet aggregability and increased bleeding times (Seiss et al. 1980; Brox et al. I98I; Thorngren \& Gustafson, 1981; Terano, et al. 1983). The effects of EPA on prostacyclin production in vivo have yet to be determined but these preliminary observations are sufficiently encouraging to sustain interest in this approach.

\section{Prostaglandins and leukotrienes in inflammation}

The role of arachidonic acid metabolism in inflammation has been the subject of considerable research in recent years and this has been comprehensively reviewed elsewhere (Higgs et al. 1983). Prostaglandins are produced when tissues are 
Vol. 44 Nutritional aspects of membrane structure and function $\quad \mathrm{I}_{5}$

disrupted or damaged and as inflammation is the response of living tissue to injury, prostaglandin synthesis always accompanies the inflammatory response. Cyclo-oxygenase products (predominantly $\mathrm{PGE}_{2}$ ) have been detected in many types of inflammation in animals and man and these observations led to the study of the role of prostaglandins in the development of the signs and symptoms of inflammation.

Some of the evidence that prostaglandins are involved in inflammation is based on their potent actions on vascular smooth muscle. Prostaglandin $E_{2}$ and prostacyclin have potent vasodilator properties and they are present in acute inflammation in sufficient amounts to account for the characteristic erythema in inflamed tissues.

Vasodilatation of peripheral arterioles increases the blood supply to post-capillary venules and enhances the effects of mediators which increase vascular permeability (Williams \& Peck, 1977). Prostaglandin production is, therefore, an important factor in plasma extravasation and oedema formation. Prostaglandin $E_{2}$ and prostacyclin also interact with other inflammatory mediators to cause hyperalgesia. For example, intra-dermal injections of E-type prostaglandins sensitize the skin to injections of bradykinin or histamine which are not normally painful (Ferreira, 1972).

Perhaps the most important evidence which establishes prostaglandins as major inflammatory mediators is the work of Vane and his colleagues which demonstrates that non-steroid anti-inflammatory drugs are selective inhibitors of cyclo-oxygenase (Ferreira et al. 1971; Smith \& Willis, 1971; Vane, 1971). This explains the anti-oedema, anti-pyretic and analgesic properties of aspirin-like drugs. Similarly, the reduction of platelet aggregation by aspirin can be accounted for by inhibition of thromboxane production.

Polymorphonuclear leucocytes contribute to cyclo-oxygenase activity in inflammation but they are also a major source of leukotriene $B_{4}$. Leukotriene $B_{4}$ is one of the most potent known chemotactic factors for leucocytes (Ford-Hutchinson et al. I980) and its production is thought to constitute a local control mechanism for the accumulation of leucocytes in inflamed tissues. Non-steroid anti-inflammatory drugs which inhibit cyclo-oxygenase do not prevent leukotriene production and this may explain why these drugs do little to modulate the leucocyte-mediated aspects of inflammatory diseases. For this reason it has been proposed that dual inhibitors of arachidonate cyclo-oxygenase and lipoxygenase could have superior therapeutic properties to existing drugs (Higgs et al. I979, 1983).

\section{The effects of dietary intake of essential fatty acids on the inflammatory response}

The first indication that dietary intake of fatty acids could modify the inflammatory response was the observation that acute inflammation was suppressed in essential-fatty-acid-deficient animals (Bonta et al. 1974). These experiments were designed to test the theory that prostaglandins were important 
inflammatory mediators and they confirmed that reduced prostaglandin synthesis was associated with reduced inflammation.

Essential fatty acid deficiency is unlikely, however, to be proposed as a treatment for chronic arthritis, but it is possible that manipulation of fatty acid intake could modify the production of prostaglandins and leukotrienes during inflammation. Leucocytes convert EPA to leukotriene $B_{9}$ which is a considerably less potent chemotactic factor than leukotriene $\mathrm{B}_{4}$ and has reduced inflammatory properties (Terano et al. 1984). Furthermore, in populations whose diet is rich in EPA there is a low incidence of rheumatoid arthritis, ulcerative colitis and psoriasis (Kromann \& Green, I980). There is also preliminary evidence that feeding EPA to laboratory animals leads to reduced oedema formation in experimental inflammation (T. Terano, J. A. Salmon, G. A. Higgs and S. Moncada, unpublished results). This effect may be explained by production of leukotriene $B_{5}$ instead of leukotriene $\mathrm{B}_{4}$; alternatively EPA displacement of arachidonic acid may result in decreased $\mathrm{PGE}_{2}$ synthesis.

\section{REFERENCES}

Bergstrom, S., Danielsson, H. \& Samuelsson, B. (1964). Biochimica et Biophysica Acta 90, 207-210.

Bergstrom, S. \& Sjovall, J. (1960a). Acta Chemica Scandinavica 14, 1693-1701.

Bergstrom, S. \& Sjovall, J. (1960b). Acta Chemica Scandinavica 14, $1701-1709$.

Bonta, I. L., Crispijn, H., Noordhoek, J. \& Vincent, J. E. (1974). Prostaglandins 5, 495-503.

Borgeat, P., Hamberg, M. \& Samuelsson, B. (1976). Fournal of Biological Chemistry 251, $7816-7820$.

Borgeat, P. \& Samuelsson, B. (1979). Proceedings of the National Academy of Sciences, USA 76, $214^{8-21} 5_{2 .}$

Brox, J. H., Kille, J. E., Gunnes, S. \& Nordoy, A. (1981). Thrombosis and Haemostasis 46, $604-6$ II.

Dyerberg, J. \& Bang, H. O. (1979). Lancet ii, 433-435.

Ferreira, S. H. (1972). Nature 240, 200-203.

Ferreira, S. H., Moncada, S. \& Vane, J. R. (197r). Nature 23r, 237-239.

Ford-Hutchinson, A. W., Bray, M. A., Doig, M. V., Shipley M. E. \& Smith, M. J. H. (Ig8o). Nature 286, 264-265.

Gryglewski, R. J., Salmon, J. A., Ubatuba, F. B., Weatherley, B. C., Moncada, S. \& Vane, J. R. (1979). Prostaglandins 18, 453-478.

Hamberg, M. \& Samuelsson, B. (r974). Proceedings of the National Academy of Sciences, USA $71,3400-3404$.

Hamberg, M., Svensson, J. \& Samuelsson, B. (1975). Proceedings of the National Academy of Sciences, USA 72, 2994-2998.

Higgs, G. A., Flower, R. J. \& Vane, J. R. (1979). Biochemical Pharmacology 28, 1959-196r.

Higgs, G. A., Moncada, S. \& Vane, J. R. (1983). In Anti-rheumatic Drugs, pp. II-36 [E. C. Huskisson, editor], Eastbourne: Praeger Publishers.

Kromann, N. \& Green, A. (1980). Acta Medica Scandinavica 208, $401-406$.

Moncada, S. (1982). British Fournal of Pharmacology 76, 3-31.

Moncada, S., Gryglewski, R. J., Bunting, S. \& Vane, J. R. (1976). Nature 276, 663-665.

Nugteren, D. H. (1975). Biochimica Biophysica Acta 380, 299-307.

Piper, P. J. \& Vane, J. R. (1969). Nature 223, 29-35.

Samuelsson, B. (1983). Science 222, S68-S75.

Samuelsson, B., Goldyne, M., Granstrom, E., Hamberg, M., Hammarstrom, S. \& Malmsten, C. (1978). Annual Review of Biochemistry 47, 997-1029. 
Vol. 44 Nutritional aspects of membrane structure and function $\quad 187$

Seiss, W., Roth, P., Scherer, B., Kurzmann, I., Bohlig, B. \& Weber, P. C. (1980). Lancet i, $44^{1}-444$.

Smith, J. B. \& Willis, A. L. (1971). Nature 231, 235-237.

Terano, T., Hirai, A., Hamazaki, T., Kobayashi, S., Fujita, T., Tamura, Y. \& Kunagai, A. (1983). Atherosclerosis 46, 321-331.

Terano, T., Salmon, J. A. \& Moncada, S. (1984). Prostaglandins 27, 217-232.

Thorngren, M. \& Gustafson, A. (1981). Lancet ii, $1190-1193$.

Van Dorp, D. A. (1967). Progress in Biochemistry and Pharmacology 3, 71-82.

Van Dorp, D. A., Beerthuis, R. K., Nugteren, D. H. \& Vonkeman, H. (1964). Biochimica et Biophysica Acta 90, 204-207.

Vane, J. R. ( I 971). Nature 231, 232-235.

Von Euler, U. S. (1937). Fournal of Physiology 88, 21 3-234.

Williams, T. J. \& Peck, M. J. (1977). Nature 270, 530-532.

Willis, A. L., Comai, K., Kuhn, D. C. \& Paulsrud, J. (1974). Prostaglandins 8, 509-519. 